\title{
A TEORIA HISTÓRICO-CULTURAL E OS PRESSUPOSTOS METODOLÓGICOS DE CELESTIN B. FREINET NA EDUCAÇÃO INFANTIL
}

\author{
LA TEORÍA HISTÓRICO-CULTURAL Y LOS PRESUPUESTOS \\ METODOLÓGICOS DE CELESTIN B. FREINET EN LA EDUCACIÓN \\ INFANTIL
}

A HISTORICAL-CULTURAL THEORY AND THE METHODOLOGICAL ASSUMPTIONS OF CELESTIN B. FREINET AND THE EARLY CHILDHOOD EDUCATION

Flávia Cristina Oliveira Murbach de BARROS ${ }^{1}$

RESUMO: Este trabalho adveio da pesquisa de Doutorado, cujo objetivo foi compreender qual o sentido que as crianças pequenas (última etapa da Educação Infantil) atribuem à escola diante das vivências a elas oferecidas por meio de diferentes propostas pedagógicas. Para esse estudo, foi selecionado a experiência de uma escola freinetiana. Primeiramente, contextualizou-se a cultura escolar, o sentido pessoal via Teoria histórico-cultural, aspectos da teoria Freinet e, finalmente, aspectos gerais da escola pesquisada / entrevistas. As vivencias contribuem para a sua formação autônoma, crítica e participativa das crianças atrelada à produção do sentido humanizador de escola.

PALAVRAS-CHAVE: Educação Infantil. Vivências. Práticas Educativas. Freinet. Produção de sentidos.

RESUMEN: Este trabajo resultó de la investigación de Doctorado cuyo objetivo fue comprender cuál es el sentido que los niños (de la última etapa de la Educación Infantil) atribuyen a la escuela según las vivencias que se les ofrecen por intermedio de diferentes propuestas pedagógicas. Para ese estudio, fue seleccionada la experiencia de una escuela freinetiana. Primeramente, se contextualizó la cultura escolar, el sentido personal vía teoría histórico-cultural, aspectos de la teoría Freinet y, finalmente, aspectos generales de la escuela analizada/entrevistas. Las vivencias contribuyen para la formación autónoma, crítica y participativa de los niños conjugada a la producción del sentido humanizador de la escuela.

PALABRAS CLAVE: Educación Infantil. Vivencias. Prácticas Educativas. Freinet. Producción de sentidos.

${ }^{1}$ Pedagoga, Mestre em Psicologia/Doutora em Educação - UNESP - Marília - Gestora FPEI/FREI. Coordenadora Acadêmica - Curso de Pedagogia. E-mail: flaviacomurbach@gmail.com 
ABSTRACT: This work is part of a Doctorate's research, which had as the main objective to understand what is the meaning of school to small children (last stage of the early childhood education) regarding to the living experiences offered to them through different pedagogical proposal. It was selected a Freinet school for this study. Firstly, the school culture was analyzed and the personal meaning in the historical cultural Theory; aspects of the Freinet theory; and last, some general aspects of the researched/ interviews. The experiences contribute to an independent, critic and participative formation of the children, attached to the creation of a humanized meaning of the school.

KEYWORDS: Early Childhood Education. Experiences. Educational Practices. Freinet. Meaning Creation.

\section{Introdução}

A referida pesquisa intitulada "Práticas Pedagógicas na Educação Infantil: a construção do sentido da escola para as crianças" ${ }^{2 \%}$, finalizada em 2014, teve por objetivo compreender qual o sentido que as crianças pequenas (última etapa da Educação Infantil) atribuem à escola diante das diversas propostas pedagógicas a elas oferecidas, ou seja, como elas percebem a escola. É oportuno examinar qual é o sentido construído pelas crianças em relação a esse espaço, considerando que as atividades relevantes ao seu desenvolvimento (atividades como diálogos entre criança-professor, brincadeiras, músicas, atividades artísticas, a roda de histórias) vêm-se reduzindo cada vez mais. O papel do espaço escolar, não somente da Educação Infantil, mas de todos os níveis de ensino, deve ou deveria ser o de oferecer às crianças e alunos em geral, a apropriação da cultura construída pelo homem ao longo da história favorecendo, assim, o processo de humanização, no qual todos podem construir e ressignificar questões que emergem na sociedade.

Como forma de obtenção dos dados, a coleta sucedeu em três escolas de Educação Infantil que empregam práticas pedagógicas diferentes: uma escola que faz uso de apostilas (de caráter privado - cidade de Assis), uma escola de tempo integral

\footnotetext{
2 Alguns ensaios do trabalho foram publicados em anais de eventos ( BARROS, Flávia Cristina Oliveira Murbach de. Qual o sentido da escola de Educação Infantil para as crianças? Algumas questões norteadoras.. 12a Jornada do Núcleo de Ensino de Marília. UNESP, p. 1 -15, 2012.), na íntegra Biblioteca da UNESP - Marília (Práticas pedagógicas na educação infantil : a construção do sentido da escola para as crianças / Flávia Cristina Oliveira Murbach de Barros. - Marília, 2014, 164 f; 30cm. e em formato livro (Barros, Flávia Cristina Oliveira Murbach de. Qual o sentido da escola para as crianças da Educação Infantil? Algumas práticas pedagógicas. Novas Edições Acadêmicas, 2015.
} 
que não se utiliza desses materiais (de caráter público - cidade de Presidente Prudente) e, por fim, uma escola Freinetiana (de caráter privado - cidade de São Carlos). A importância de pesquisar várias vertentes metodológicas e práticas pedagógicas justifica-se pelo fato de podermos também constatar o que as propostas tendem a oferecer em relação à formação integral das crianças. Considerando a amplitude da coleta de dados, foram empregados alguns instrumentos: a observação da estrutura física e humana e as diversas relações ali vivenciadas entre crianças e seus pares e criança-adulto; $o$ diário de campo, como peça fundamental para o registro dessas observações; a realização de entrevistas semiestruturadas, e o desenho $e$ a dramatização. As atividades realizadas com as crianças, assim como o roteiro das entrevistas foram dirigidos pelas seguintes questões: O que significa a escola para você? O que você pensa sobre ela? Quais as atividades que realiza na escola?

Os procedimentos foram efetivados durante o segundo semestre de 2011 com uma turma por escola, pertencentes à última etapa da Educação Infantil, o que totaliza a participação de aproximadamente quarenta e oito crianças, durante o período de três a quatro semanas por escola. Como resultados das observações, percebe-se que a cultura escolar de cada escola direciona a organização das práticas pedagógicas e as vivências oferecidas às crianças da Educação Infantil, o que colabora com a forma com que elas apreendem a escola e lhe atribuem sentido. A última etapa da pesquisa se pautou na análise dos dados que, construídos com as crianças, foram analisados à luz da teoria histórico-cultural, que tem como seu principal represente Lev. S. Vigotsky (1896-1934). Considerando a grande gama de dados coletados durante a pesquisa, foram selecionados da escola Freinet algumas caracterizações gerais e duas entrevistas realizadas com as crianças participantes ${ }^{3}$. Nessa perspectiva, o presente artigo traz uma pequena introdução sobre "A cultura escolar: O educador e a criança" sob o viés conceitual sobre a cultura escolar, e num segundo momento, aborda a seguinte indagação "Qual o sentido da escola de Educação Infantil para as crianças? atrelando a discussão sobre a produção de sentido pessoal pelo homem por meio de suas vivências na perspectiva da teoria histórico-cultural. Em seguida o tópico "Vivências na escola Freinet: por uma prática pedagógica humanizadora" tem por objetivo contextualizar, de forma breve, princípios e práticas do pedagogo Celestin B. Freinet e trazer, para dar mais vida ao trabalho, alguns dados de pesquisa - a escola/caracterizações gerais e as entrevistas com

${ }^{3}$ Participaram da coleta de dados realizada na escolar Freinet onze crianças. 
as crianças. Para fechamento deste artigo construiu-se algumas considerações "no intuito de traças as relações estabelecidas entre a cultura escolar e a influencia no desenvolvimento das práticas pedagógicas e vivencias oferecidas as crianças como eixos articuladores da produção de sentido pessoal das crianças em relação a escola.

\section{A cultura escolar: o educador e a criança}

Diante do emaranhado de leis infundadas e preparadas apenas para atender às necessidades da política vigente (BARROS, 2009), observa-se seus reflexos no espaço escolar, descaracterizando-o de sua função real - a de, segundo a teoria históricocultural, humanizar as pessoas, ou seja, fazê-las sair do plano de constituição biológica e formar qualidades humanas na medida em que vão se apropriando da cultura mais elaborada, construída historicamente por homens e mulheres, o que implica no relacionamento da criança tanto com seus pares, quanto com adultos mais experientes. De acordo com Leontiev (1978, p. 261), “[...] o homem é um ser de natureza social, que tudo o que tem de humano nele provém da sua vida em sociedade, no seio da cultura criada pela humanidade".

Entretanto, a realidade da maioria das escolas brasileiras de Educação Infantil revela o processo inverso. A falta de estrutura física e humana adequada para satisfazer as necessidades específicas da infância, decorrida da história das instituições direcionadas ao atendimento infantil, a má administração das políticas públicas, somadas à cristalização das concepções de criança, desenvolvimento e educação, revigoram esse processo. Assim "[...] Conhecer a história das instituições e das políticas públicas na área, traçada dentro das demais lutas sociais, pode apontar-nos novos caminhos, se soubermos compreender as contradições em meio às quais elas foram gestadas”. (OLIVEIRA, 2002, p. 57-56).

Todas essas contradições devem servir de premissas para investigações mais precisas sobre o que ocorre no interior da escola e como sua cultura interna interfere no curso do desenvolvimento das práticas pedagógicas, ou seja, quais são as condições oferecidas às crianças, para que elas se apropriem da cultura mais elaborada e criem, para si, as qualidades humanas. Segundo Mello (2007, p. 85), a escola 
Pode intencionalmente organizar as condições adequadas de vida e educação para garantir a máxima apropriação das qualidades humanas - que são externas ao sujeito no nascimento e precisam ser apropriadas pelas novas gerações por meio de sua atividade nas situações vividas coletivamente.

O comprometimento das condições adequadas ao desenvolvimento integral das crianças afeta diretamente o que lhes é proposto, reduzindo-se, muitas vezes, ao oferecimento de atividades estereotipadas e padronizadas, o que empobrece a função primordial da escola - a de humanizar.

A escola de Educação Infantil, espaço fundamental para o desencadeamento de novas relações entre crianças e seus pares e com adultos não familiares, como também enquanto um lugar em potencial para o desenvolvimento físico, social e cultural dos pequenos, está cada vez mais afetada por essas condições atuais. Uma das grandes preocupações da Educação Infantil é a antecipação do processo de alfabetização, que vem provocar a diminuição de grande parte de atividades essenciais para o desenvolvimento integral da criança pequena. A redução das brincadeiras, músicas, atividades em que envolvam a arte e a criação, a contação de histórias, atividades de expressão, o próprio tempo da atividade livre, em que as crianças possam interagir, dialogar e até mesmo se conflituar, se concretizam em detrimento das novas necessidades da escola de Educação Infantil contemporânea. Nesse sentido, a cultura escolar se modifica e passa a se configurar em busca da formação do homem produtivo e a-crítico sobre a realidade.

O conceito de cultura escolar já vem sendo discutido por muitos estudiosos, como Chervel (1990), Forquin (1993), Julia ( 2001 ), Viñao Frago ( 1995 ), entre outros. Na literatura norte-americana, destacam-se as pesquisas de Shepel (2008), que, embasadas em outros autores e na teoria da teoria histórico-cultural, mostram diferentes enfoques de análise. Salientam McBrien e Brandt (1997, apud SHEPEL, 2008, p. 1, tradução nossa):

Cultura escolar refere-se à soma dos valores, crenças, culturas, práticas de segurança, e estruturas organizacionais dentro de uma escola que fazem com que ela funcione e reaja de maneiras particulares. Algumas escolas dizem ter um ambiente de carinho, que reconhece as crianças e as trata como indivíduos, enquanto outros podem ter a sensação de estruturas autoritárias onde as regras são rigorosamente aplicadas e o controle hierárquico é forte. Práticas de ensino, a diversidade, e as relações entre administradores, professores, pais e alunos contribuem para a cultura escolar. 
A definição acima retoma a importância para o conceito de várias questões de ordem particular, provindas dos sujeitos que compõem cada escola (crenças, valores...), que, ao serem dispersas na estrutura organizacional, condicionam a construção de maneiras particulares de construir as relações administrativas, afetivas ou pedagógicas, entre os membros da comunidade escolar.

Outra definição de Terry Deal e Kent Peterson (1993, apud SHEPEL, 2008, p.1) dá conta de que a cultura escolar é “uma realidade interior”. Robbins e Alvy (1995, p. 23, apud SHEPEL, 2008, p.1, tradução nossa) completam essa definição, afirmando: "Esta realidade interior reflete o que os membros da organização se preocupam, o que eles estão dispostos a gastar tempo a fazer, o que e como eles comemoram, sobre o que falam".

As definições podem interagir, à medida que considerarmos que o cerne desse conceito se relaciona com várias questões perpendiculares de ordem coletiva e individual. Fatores como a estrutura da política educacional vigente, que, por sua vez, organiza as estruturas gerais da escola e seus regimentos, influenciam diretamente em cada âmbito escolar. Mas seu impacto difere, visto que suas particularidades - como como horários, metodologias, concepções de criança, desenvolvimento e educação, além das histórias de vida de crianças, professores, funcionários e pais - se articulam. Todos esses fatores, ao se posicionarem num determinado espaço, formam uma cultura escolar específica que se reflete diretamente nas relações alí gestadas, repercutindo ainda nas vivências que são oferecidas às crianças. Todavia, cabe a indagação de como os professores e as crianças, protagonistas desse espaço, se configuram nesse processo?

A complexidade do espaço da escola também redireciona o papel do professor e da criança nas relações de apropriação do conhecimento. As práticas pedagógicas envolvidas por essa cultura escolar, muitas vezes mostram-se engessadas por modismos ou concepções cristalizadas e históricas e comprometem a possibilidade de o educador realizar atividades capazes de levar a criança a se apropriar dos bens acumulados historicamente pela humanidade. Em alguns casos, quando o professor possui a formação adequada e consegue enxergar possibilidades diferenciadas de trabalho, ele se depara com os regimentos internos da escola, que dificultam a efetivação de suas intenções pedagógicas.

Ao considerarmos que a escola possui uma cultura interior que influencia nas vivencias oferecidas às crianças, ou seja, quais práticas pedagógicas têm sido ofertadas 
e em quais objetivos, torna-se necessário aprofundar o ponto-chave de nosso trabalho: Qual o sentido que as crianças atribuem à escola, diante das vivências que são oferecidas a elas?

\section{Qual o sentido da escola de Educação Infantil para as crianças?}

Diante de tantas falácias de ordem política, econômica e pedagógica, refletidas no interior da escola de Educação Infantil, como as crianças percebem esse espaço? Qual o sentido que elas atribuem à escola? O sentido atribuído pelas crianças dependerá das diversas relações vivenciadas por elas neste espaço, em destaque, como e quais atividades lhes são oferecidas.

A teoria histórico-cultural propõe a categoria de atividade como fundamental, destacando que é por meio dela que o homem constrói sua história individual e coletiva. Segundo Davidov (1988), a atividade é toda a prática humana, de caráter históricosocial que atua como elemento estruturador da psique.

A realização da atividade humana depende das necessidades sociais determinadas historicamente. O sujeito executa ações conscientes para alcançar um determinado objetivo. Este sofre modificações a partir das relações estabelecidas socialmente, determinando novos motivos e novas atividades. Leontiev (1978, p. 118, tradução nossa) ressalta:

Estas relações são as decisivas no plano psicológico. O que ocorre é que para o próprio sujeito a apreensão e a busca de objetivos concretos, o domínio dos meios e operações da ação é um modo de afirmar sua vida, de satisfazer e desenvolver suas necessidades materiais e espirituais, objetivadas e transformadas nos motivos de sua atividade.

De acordo com Leontiev (1978), a tomada de consciência dos motivos se configura nas vivências (desejo, interesse, paixão), que são consideradas determinantes para o plano psicológico. As circunstâncias objetivas e as ações realizadas nesse processo configuram o sentido pessoal que, muitas vezes, não coincide com os significados objetivos. 
Vale lembrar que as transformações da sociedade feudal para sociedade mercantil motivou a criação de novas formas de pensar e agir, instaurando novos motivos e necessidades até então inexistentes. $\mathrm{O}$ homem, que antes produzia para sua própria subsistência, passa a vender sua mão-de-obra, tornando-se assalariado. Nesse movimento de transformações, ele começa a realizar funções operárias de maneira racional, processo no qual modifica o sentido de sua atividade produtiva. Assim, Marx e Engels (1984, p. 830) salientam:

O processo que cria o sistema capitalista consiste apenas no processo que retira do trabalhador a propriedade de seus meios de trabalho, um processo que transforma em capital os meios sociais de subsistência e os de produção e converte em assalariados os produtores diretos.

Essa nova relação do homem com sua atividade produtiva provocou contradições entre o sentido pessoal de suas atividades e seus significados sociais objetivos, o que interfere na formação de sua consciência cada vez mais alienada e fragmentada. Em decorrência, Leontiev (1980, p. 114, tradução nossa) deixa claro que “as significações constituem importantíssimos componentes da consciência humana".

O significado parte do estabelecimento social do signo linguístico. As significações estão subordinadas pelas leis histórico-culturais, e é no movimento das vivências ideológicas da sociedade que o processo de consolidação dos significados vaise constituindo. "A significação é a generalização cristalizada da realidade, fixada por uma palavra ou combinação de palavras; é a forma ideal, a representação da experiência social" (LEITE, 2005, p.44).

A linguagem é um importante mediador, um sistema de signos carregado de significações, que serão absorvidos pelo indivíduo e dependerão do “[...] sentido subjetivo e pessoal que estas tenham para ele" (LEITE, 2005, p. 51), lembrando que o indivíduo é pertencente a um contexto social, político e histórico, portanto, um sujeito histórico-cultural. Baseando nas leituras de Paulhan, Vigotski apresenta as definições para as categorias do sentido e significado da palavra:

Para Paulhan, o sentido da palavra é a soma de todos os eventos psicológicos evocados em nossa consciência pela palavra. Por conseguinte, o sentido da palavra é sempre uma formação dinâmica, variável e complexa que tem várias zonas de estabilidades diferentes. O significado é apenas uma dessas zonas de sentido, a mais precisa e consistente. A palavra adquire o sentido em seu contexto e, como se sabe, contextos diferentes fazem surgir sentidos diferentes. significado diferente em contextos diferentes. Pelo contrário, o significado é inalterado e estável em todas as mudanças de contexto. As variações 
no sentido representam o principal fator na semântica da linguagem. O verdadeiro significado da Palavra não é constante. (VIGOTSKI, 2001, p. 333, tradução nossa).

Os significados se articulam a partir da relação do sujeito e a realidade objetiva, e o sentido vincula-se com a realidade da vida pessoal de cada sujeito, através de seus motivos particulares.

Ao pensar na escola, questiona-se: como se organiza a construção do sentido da escola de Educação Infantil pela criança, considerando que as atividades relevantes ao seu desenvolvimento vêm-se reduzindo tão intensamente?

Leontiev (1978b) esclarece que as categorias sentido e significado são conteúdos da consciência e que os significados sociais são construídos de forma coletiva e histórica. Eles estabelecem o nível de conhecimentos objetivos que podem ser adquiridos pelo homem, bem como o conteúdo de suas objetivações.

Os significados levam uma vida dual. São produzidos pela sociedade e possuem sua própria história no desenvolvimento da linguagem, no desenvolvimento das formas de consciência social [...] Nesta sua existência objetiva se subordinam às leis histórico-sociais e por sua vez, à lógica interna de seu próprio desenvolvimento. (LEONTIEV, 1978, p.116, tradução nossa).

São subsídios que assinalam o aspecto lógico dos significados, porém, estes necessitam de outro movimento para que funcionem na atividade da consciência dos indivíduos, o sentido pessoal, processo pelo qual os significados passam a permanecer para o sujeito, levando em consideração que são as vivências sociais que irão determinar uma dada significação. Conforme Leontiev (1978, p. 120, tradução nossa, grifo no original), "[o] sentido pessoal é o que cria a parcialidade da consciência humana".

As vivências individuais e coletivas são responsáveis pelas transformações dos significados sociais em sentidos pessoais. É por meio dessas atividades que ocorre seu processo de humanização. Nessa perspectiva, é fundamental que as mediações dos educadores se voltem para esse processo, de maneira que as crianças estabeleçam as conexões necessárias. Dessa forma “ Tomar os motivos e as necessidades das crianças como eixos norteadores do trabalho pedagógico é fundamental para o desenvolvimento de um trabalho intencional que vislumbre o desenvolvimento integral da criança"..(BARROS, 2014, p. 30).

Somos constituídos segundo a teoria-histórico-cultural pelas relações históricas e sociais, em tempos, espaços e circunstancias diversas, e que os motivos que geram a atividade humana são os principais responsáveis aos sentidos atribuídos a ela. Nessa 
perspectiva devemos nos deter sobre o que está sendo oferecido as crianças pequenas no espaço da Educação Infantil. Para melhor compreensão deste preambulo, trago um breve relato da prática pedagógica e dos princípios do pedagogo Celestin B. Freinet no intuito de articulá-lo a pesquisa de campo que será mostrada posteriormente.

\section{Vivências na escola Freinet: por uma prática pedagógica humanizadora}

Nasceu no ano de 1896, na região de Provença, sul da França, o pedagogo Célestin B. Freinet. Segundo Sampaio (1989) suas vivências escolares foram desastrosas, um dos fios condutores que o levaram a repensar, quando adulto, a escola e suas práticas educativas. Iniciou o curso de Magistério mas não o finalizou devido seu alistamento durante a primeira Guerra Mundial (1914 - 1918).

Mesmo sem estar cursando o Magistério, Freinet continuou dedicar-se à Educação estudando as questões atuais de sua época, o que deu origem a várias obras pedagógicas que se voltaram para questões político-educacionais demarcando sua militância por uma educação transformadora, que pudesse contribuir para a formação de cidadão autonômicos e críticos diante da realidade (SAMPAIO, 1989). Para isso, era necessário atender as necessidades infantis e as motivassem por meio de atividades instigantes.

Conforme Sampaio (1989) a autora, Freinet opunha-se de forma acirrada aos métodos tradicionais de ensino de então, os ditos "manuais". Sua oposição as correntes educacionais da época (escola renovada e ativa e escola opressiva e tradicional) agravouse levando-o a contestar por meio do slogan "Abaixo aos manuais" (SILVA; BARROS \& RAIZER, 2012).

Nessa perspectiva, Freinet criou algumas técnicas de trabalho norteadas pelos princípios de cooperação, livre expressão, tateio experimental, trabalho e autonomia.

Para o educador francês, (1973, p. 36), “[a] inteligência manual, artística, científica, não se cultiva de modo algum apenas com o uso das ideias, mas por meio da criação, do trabalho, da experiência”. Barros (2014, p. 47) elucida que para Freinet a escola está vinculada à vida dos alunos. Nesse sentido, pode-se dizer, segundo a autora, que o trabalho e a livre expressão são conceitos essenciais em sua proposta pedagógica, tendo por eixo orientador a experimentação e a cooperação. "É por meio da 
experimentação que a criança se apropria dos objetos construídos pelo homem e das relações que eles estabelecem com o mundo".

Freinet trouxe grandes contribuições para um pensar sobre uma educação humanizadora, proporcionando às crianças possibilidades de explorar, experimentar, imaginar, se expressar e ressignificar conceitos da própria vida. Quando falamos em educação humanizadora, referimo-nos àquela que cria condições para que os alunos possam desenvolver suas potencialidades por meio da apropriação dos bens materiais e não materiais produzidos pelo homem ao longo da história (MELLO, 2007).

Freinet com seus princípios e práticas pedagógicas traz como diferencial a criança como protagonista de seu processo de aprendizagem, mas com a mediação do professor. Nesse sentido, o educador tem o papel de proporcionar e conduzir vivencias enriquecedoras às crianças a ponto que as instiguem a refletirem e a pensarem conscientemente sobre o seu papel na sociedade. Assim, contribuindo com a construção de um sentido humanizador de escola, espaço de múltiplas dimensões que deve ou "deveria" proporcionar às crianças o conhecimento científico de forma que ressignificassem a sua própria vida e o pensar conscientemente sobre ela.

Podemos então retomar a pergunta principal da pesquisa de Doutorado aqui salientada: Qual o sentido que as crianças pequenas (última etapa da Educação Infantil) atribuem à escola, diante das vivências oferecidas a elas por meio de diferentes propostas pedagógicas? Como se trata de um recorte da pesquisa, reelaboramos a pergunta: Qual o sentido que as crianças pequenas (última etapa da educação Infantil) pertencentes a uma escola cuja metodologia de trabalho pedagógico pautada nos pressupostos metodológicos de Freinet, atribuem à escola diante das vivencias oferecidas a elas?

Em detrimento da segunda pergunta, seguem alguns dados para reflexão.

A escola pesquisada se localiza em uma cidade do interior do estado de São Paulo e atua nos seguimentos desde a Educação Infantil (berçário) até o nono ano do Ensino Fundamental com turmas nos períodos matutino e vespertino. As famílias tem livre acesso à escola o que proporciona encontros diários entre as famílias e crianças de diferentes faixas etárias. No período da coleta de dados da pesquisa (2011) somavam-se 25 classes compostas por 413 alunos.

Outros espaços como secretaria, diretoria, almoxarifado, biblioteca, sala de teatro, sala de vídeo, sala de artes compõem a escola. Muitos recursos são disponibilizados para professores e alunos como projetos de slides, jogos diversos, 
filmadoras, xerocopiadoras, etc e uma peça fundamental: o limógrafo ${ }^{4}-$, utilizado, principalmente com as crianças pequenas, para a compreensão de seu uso e como peça fundamental do desenvolvimento da imprensa escolar, uma das Técnicas Freinet.

A sala da turma pesquisada, (assim como na maioria) é feita de madeira, arejada e com grandes janelas. Um armário com materiais diversos como lápis de cor, folhas e cadernos fica localizado em uma das paredes com livre acesso as crianças. As carteiras são organizadas em quatro grupos de quatro, para que trabalhem no formato de ateliers. $\mathrm{Na}$ mesa da professora encontra-se um computador no qual as próprias crianças registram suas novidades discutidas na roda, para a impressão. A sala é decorada com as atividades construídas pelas crianças, o que proporciona um espaço de identidade própria. O espaço externo da escola é composto por uma grande área verde com arvores, grama, terra e brinquedos de madeira.

As aulas de Educação Física, dança, artes e música são ofertadas às crianças sendo o Karatê e o balé atividades extracurriculares. Sobre as famílias da comunidade escolar, pertencem à classe média e média baixa, os pais, de um modo geral são professores, universitários, do Ensino Médio e Fundamental, pequenos empresários, comerciários, bancários, médicos, servidores públicos, engenheiros, dentistas, entre outras atuações. (BARROS, 2014, apud, PLANO ESCOLAR, 2011).

Durante as observações foi possível perceber a constante participação das famílias no espaço escolar, não somente acompanhando os filhos até as suas salas como também em terem a liberdade de acompanharem e a participarem das diversas atividades oferecidas no cotidiano da escola como as reuniões pedagógicas, as festas cooperativas e a Associação de Pais e Mestres, além de passeios coletivos entre escola e famílias.

Esta pequena contextualização da escola é fundamental para compreendermos um pouco de sua organização em relação ao que se oferece para as crianças na perspectiva Freinetiana. Dessa forma, adentramos, ainda que de forma simplista, na cultura escolar estabelecida neste espaço, acrescida da concepção de criança e educação que ela carrega. Assim, percebe-se um espaço rico e propício a troca de experiências que poderão ser melhor avistadas durante os dados coletados.

${ }^{4} \mathrm{O}$ limógrafo é uma imprensa artesanal criada por Freinet destinada a produção dos textos livres e do jornal escolar. A escola possui três itens. 
Como já ressaltado anteriormente, a coleta de $\operatorname{dados}^{5}$ foi realizada por meio de alguns instrumentos tais como: a observação da estrutura física e humana, as diversas relações vivenciadas ali na escola entre crianças e seus pares e crianças e adultos, o diário de campo como instrumento de registro dessas observações; a realização de entrevistas semiestruturadas, o desenho e a dramatização. Participaram da pesquisa cerca de onze crianças. Considerando a amplitude dos dados nos deteremos apenas em algumas entrevistas a fim de ilustrar o presente trabalho por meio das experiências vividas pelas crianças no qual foram relatadas por elas. Dessa forma, traçamos a possibilidade de travar uma discussão sobre a proposta pedagógica da escola pesquisada na perspectiva de uma cultura escolar que vislumbre um sentido humanizador de escola para as crianças.

As entrevistas foram realizadas individualmente no espaço da biblioteca da escola e todas foram gravadas. Mas antes desse momento individual, organizou-se uma roda com todas as crianças da turma, dirigida por alguns questionamentos levantados pela pesquisadora: Qual o significado da escola para você? O que vocês pensam sobre a escola? As crianças mostraram-se envolvidas com as questões perguntando sobre como seria a entrevista individual e que gostariam de saber o que é uma entrevista. Fizemos a discussão sobre os procedimentos e objetivos da atividade e em seguida a pesquisadora os conduziu para uma conversa na biblioteca. Todos queriam ser os primeiros, mostravam-se curiosos e instigados. Segue algumas das entrevistas extraídas da tese (BARROS, 2014, p. 76-77):

Pesquisadora: Vamos lá. Por que você vem pra escola?

Jonas $^{6}$ : Pra gente aprender.

Pesquisadora: É, o que você aprende aqui?

Jonas : As coisas.

Pesquisadora: Que coisas? Me conta que eu quero saber.

Jonas : Sítio, a gente aprende o Sítio Do Pica-Pau a :: textos...

Pesquisadora: Textos? Que textos que você aprende aqui?

Jonas : $\tilde{A}::$, o do Z, o do P, o meu, a $::$, o do G, todos a gente faz.

Pesquisadora: E você gosta de fazer os textos?

\footnotetext{
${ }^{5}$ A análise e discussão dos dados forma organizados da seguinte forma: a rotina da turma pesquisada, o trabalho pedagógico, a entrevista com a professora, entrevistas com os estudantes, dramatização e desenho. Neste artigo nos deteremos apenas nas entrevistas realizadas pela pesquisadora juntamente com as crianças para a coleta de dados.

${ }^{6}$ Todos os nomes apresentados são fictícios, zelando pelo anonimato das crianças.
} 
Jonas: É. Tem um carinha que fica apagando as letrinhas $e$ :: e o outro carinha fica escrevendo.

Pesquisadora: E vocês gostam dessa atividade?

Jonas: Sim.

Pesquisadora: O que vocês aprendem com essa atividade?

Jonas: Ah..a gente aprende a ler e as letras.

Pesquisadora: Você lembra de algum texto que você gostou mais?

Jonas: É claro, é o meu. ((risos))

Pesquisadora: Fora o seu tem outro que você gostou?

Jonas: O do Zé, o do Zé. É assim, o kung-fu, ele pegou um fogo ou uma bomba na mão e saiu fogo, é:: esse é o mais engraçado. ((risos))

Pesquisadora: E tem algum lugar em que você gosta mais de ficar, que você gosta aqui na escola?

Jonas: O parque e a:: minha sala aqui.

Pesquisadora: Por que você gosta da sua sala?

Jonas: Porque tem um monte de projetos e também tem o parque que eu também gosto.

Pesquisadora: Qual o projeto que vocês estão fazendo agora?

Jonas: Aha, de texto nenhum, que já acabou. Mas a gente já fez o saci pererê pra caçada, que a gente vai fazer, e a gente já pintou as garrafas, e a gente já fez o saci pererê pra gente caçar.

Pesquisadora: Você gosta do que tem aqui na escola ou falta alguma coisa?

Jonas: Falta:: falta todos os meus amigos do planeta. ((risos)) Diário de campo, setembro de 2011).

Na fala de Jonas percebeu-se o envolvimento com a produção de textos sendo que o aluno enfatizou sua própria produção "o meu texto". É importante frisar que a escola realiza desde a Educação Infantil as técnicas pedagógicas de Freinet e uma delas é o Jornal de Parede, cujas crianças por meio de suas notícias e curiosidades são instigadas a produzirem seus próprios textos, além do uso do limógrafo, instrumento utilizado por Freinet em seu tempo de professor para que as crianças construíssem o jornal. Barros (2014, p. 78) destaca a importância de as crianças produzirem seus desenhos, textos, pinturas, bem como outras atividades, não excetuando, todavia, o trabalho do professor enquanto mediador das aprendizagens e elo entre elas e os bens culturais historicamente produzidos.

Freinet (1978) deixa claro, em seu legado, que o tateio experimental é fundamental para a apropriação dos conceitos pelas crianças e a experiência delas com 
os objetos tornam-se essenciais. O protagonismo da criança durante as atividades pedagógicas é o motriz para a construção de sua autonomia.

A participação em projetos também foi destacada pela criança como algo importante e instigante. O brincar também é destacado por ela que mostra o reconhecimento da relevância da atividade pela escola. Como afirma Vygotski (2008, p. 25), "[n]a idade pré-escolar, surgem necessidades específicas, impulsos específicos que são muito importantes para o desenvolvimento da criança e que conduzem diretamente à brincadeira".

Em seguida, segue um pequeno diálogo com Carlos, que reitera a discussão feita por Jonas sobre as atividades realizadas na escola In (BARROS, 2014, p. 78):

Pesquisadora: Fala uma coisa pra mim, por que você vem aqui pra escola?

Carlos: Pra aprender.

Pesquisadora: Pra aprender? Conta da sua escola pra mim? O que você aprende aqui?

Carlos: Do caça saci, da lenda, é::: do Monet. [...]. (Escola 1, Diário de campo, setembro de 2011).

A conversa com Carlos denota diversas atividades por ele vividas como a pintura, a apropriação da arte ao citar o pintor Monet, o destaque às lendas folclóricas e o saci. O desenvolvimento dessas atividades foram presenciadas pela pesquisadora. Toda a turma (em momentos diferentes, sala organizada pelos ateliers na perspectiva de Freinet) participou de uma roda da conversa sobre a vida e obra de Monet alicerçada pelo livro Lineia no Jardim de Monet $^{7}$. Esse momento foi crucial para que as crianças fizessem questionamentos sobre o pintor e suas obras. No dia anterior, elas escolheram qual obra queriam reproduzir no intuito de que aprendessem algumas técnicas artísticas bem como sobre a relevância dos trabalhos do pintor para humanidade. No momento da realização da atividade experimental as crianças demostravam-se atentas às técnicas e discutiam sobre o pintor e a obra. A questão do Tateio experimental também foi muito presente nesta atividade. A professora foi uma importante mediadora pois alimentava os questionamentos das crianças como também trazia materiais diversos sobre a discussão em dias posteriores.

Carlos ainda ressalta in (Barros, 2014, p. 79):

${ }^{7}$ BJORK, C. Linéia no jardim de Monet. São Paulo: Salamandra, 1992. 
Pesquisadora: O que você gostaria de fazer aqui na escola e você não faz? Não pode fazer?

Carlos: É:: brincar de:::ninja

Pesquisadora: Ah! Brincar de ninja. Por que você gostaria de brincar de ninja?

Carlos: Por quê? Porque eu ia... porque eu tava indo pra prova final do ninja.

Pesquisadora: E o que significa a escola pra você?

Carlos: Que é legal. Dá pra brincar de tudo. [...] (Escola freinetiana, coletado em setembro de 2011).

Nas atividades de experimentação ficam evidentes no relato das crianças: as do caça-saci, a exploração sobre as obras e as técnicas de pintura de Monet e a produção e em destaque, "meu próprio texto". Nessa perspectiva:

A experimentação, sempre que isso for possível, que pode ser tanto observação, comparação, controle, quanto prova, pelo material escolar, dos problemas que a mente se formula e das leis que ela supõe ou imagina. A criação, que, partindo do real, dos conhecimentos instintivos ou formais gerados pela experimentação consciente ou inconsciente, se alça, com a ajuda da imaginação, a uma concepção ideal do devir a que ela serve. homens, outras raças, outras gerações (FREINET, 1998, p. 354-355, grifos do autor).

A relevância da produção de seu próprio texto exposta por Jonas com ênfase, mostra que a experimentação, a criação e a documentação movimentam esse percurso autônomo da criança e que não se fixa apenas em uma simples produção de texto, mas em um processo independente de criação.

O brincar como atividade essencial para o desenvolvimento infantil também é destacado pelas crianças o que evidencia a escola como espaço de "brincar de tudo". (Jonas). As crianças também destacam a presença dos amigos durante as brincadeiras e as atividades evidenciadas por elas, o que mostra a relação com a sociabilidade e cooperação entre eles. O protagonismo ativo das crianças é evidente durante os relatos, o que traz à tona os princípios de autonomia e livre expressão que Freinet preconizava.

Por meio da pequena contextualização da escola e das entrevistas percebeu-se algumas premissas para fecharmos este artigo "Qual o sentido da escola pesquisada para as crianças que nela frequentam?" 


\section{Algumas Considerações}

O presente artigo apresentou uma pequena introdução sobre a cultura escolar no intuito de situar o leitor sobre o referido conceito e o objetivo da pesquisa aqui apresentada. A cultura de cada escola é um eixo desencadeador das concepções de criança e educação, que contribuem, significativamente, com as vivências oferecidas às crianças que devem ser reconhecidas como possuidoras de direitos e protagonistas dentro do espaço de ensino e aprendizagem. Para isso, devem ser oferecidas a elas vivências humanizadoras capazes de deixá-las intrigadas ao ponto de quererem saber mais sobre o mundo. O conhecimento deve extrapolar as paredes da escola, para que assim sejam produzidos sentidos humanizadores em relação a este espaço. Como reporta Leontiev (1978), as vivências individuais e coletivas são responsáveis pelas transformações dos significados sociais em sentidos pessoais. Nessa perspectiva, uma prática pedagógica voltada para a formação de seres críticos, autonômicos e políticos é capaz de transformar os significados sociais e gerar sentidos humanizadores da escola e da vida. Assim, torna-se fundamental destacar alguns pontos dos dados aqui apresentados que contribuem para ratificar a relevância das experiências freinetianas para a formação de um sujeito ativo e transformador. Percebemos que a escola pesquisada embasa seus trabalhos pedagógicos nos princípios de Freinet como a autonomia, livre expressão e cooperação. $\mathrm{O}$ tateio experimental também fica evidente nos relatos das crianças, como um momento de criação e imaginação capaz de ressignificar suas reflexões em relação a escola. Jonas ao citar que "o seu texto" é o que ele mais gosta, demonstra que a atividade de produção textual faz sentido para ele, é protagonista em sua criação. A presença dos amigos também fica evidente, as parcerias para os trabalhos em grupo solidificam a cooperação no desenvolvimento das atividades. O brincar coletivo também é exposto pelas crianças como atividade que acontece de forma intensa na escola, o que mostra a liberdade da atividade, tão significativa para as crianças contribuindo para o seu desenvolvimento integral. A apropriação da cultura humana produzida pelo homem ao longo da história e reportada pelas crianças durante as entrevistas, o destaque as lendas folclóricas como o saci e a atividade realizada sobre a vida e obras de Monet retratam a preocupação da escola em oferecer às crianças essa apropriação o que também culmina um trabalho com a livre expressão, a arte, a ciência. Para que essas vivências sejam significativas a ponto de transformá-las internamente em relação a sua reflexão sobre o mundo e a vida, torna-se 
necessário que a escola seja organizada em uma perspectiva humanizadora, o que implica não adequar-se aos modismos educacionais de maneira a atender as necessidades específicas das crianças, o que implica um projeto político pedagógico que vislumbre o objetivo de formar cidadãos autônomos e capazes de discernirem o que está a sua volta.

Para fechar este artigo trago um acontecimento interessante, que pode servir de ilustração para nossa discussão. Em outubro de 2016 retornei a essa escola para levar alunos do Curso de Pedagogia para conhecerem o espaço. Estava eu em pé, assistindo uma representação teatral das crianças, quando avistei alguns rostos conhecidos. E de repente ouvi: "É a professora da entrevista", do gravador". Nesse momento fiquei perplexa, por ter sido reconhecida pelas crianças participantes da pesquisa que, no período, tinham aproximadamente quatro anos de idade. $\mathrm{O}$ menino que me reconheceu era o Carlos, um de nossos entrevistados. Carlos me levou até as outras crianças e disse... "É ela...a professora da entrevista". Carlos e os colegas disseram: "Professora venha ver nossa exposição, agora estamos estudando os continentes e os países. Fizemos alguns". Venha ver, nós fizemos". Este encontro mostrou o quanto a escola é significativa para eles e que a minha presença em 2011 foi uma parceria, o que revela a escola como espaço de reciprocidade entre adultos e crianças. Esse encontro me proporcionou não só boas lembranças mas trouxe-me novos sentidos para a vida. Humanizar significa torna-se humano, um humano protagonista de sua história, e a escola pode ser a mediadora neste processo.

\section{Referências}

BARROS, F. C. O. M. de. Qual é o sentido da escola para as crianças da Educação Infantil? Algumas práticas pedagógicas. Novas Edições Acadêmicas, São Paulo, 2015.

BARROS, F. C. O. M. Cadê o brincar? da Educação Infantil para o Ensino Fundamental. Cultura Acadêmica, São Paulo, 2009.

BARROS, F. C. O. M. Qual o sentido da escola de Educação Infantil para as crianças? Algumas questões norteadoras. In: I Congresso Internacional sobre a Teoria Historico-cultural e $11^{\circ}$ Jornada do Núcleo de Ensino de Marilia. Marilia: Unesp, 2012. v. 11. p. 1-15. 
BARROS, F. C. O. M. Práticas pedagógicas na educação infantil: a construção do sentido da escola para as crianças 2014, 164f Tese.Doutorado em Educação Universidade Estadual Paulista, Faculdade de Filosofia e Ciências. Marília, 2014.

SILVA, G. F. BARROS, F. C. O. M de; RAIZER, C. M. As implicações pedagógicas de Freinet para a educação infantil: das técnicas ao registro. In: VI COPEDI Congresso Paulista de Educação Infantil e II Congresso Internacional de Educação Infantil. São Paulo: USP, 2012.

BJORK, C. Linéia no jardim de Monet. São Paulo: Salamandra, 1992.

CHERVEL, A. História das disciplinas escolares: reflexões sobre um campo de pesquisa. Porto Alegre: Teoria \& Educação, v. 2, p. 177-229, 1990.

DAVIDOV, V. La ensenãnza escolar y el desarrollo psiquico: investigación teórica y experiental. Progreso, Moscú: 1988.

DEAL, T.; PETERSON, K. Strategies for building school cultures: Principals as symbolic leaders. In: SASHKIN, M.; WALBERG, H. (Eds.). Educational leadership and school culture. Berkeley, CA: McCutchan, 1993. p. 89-99.

FORQUIN, J-C. Escola e cultura: as bases sociais e epistemológicas do conhecimento escolar. Porto Alegre: Artes Médicas, 1993.

FREINET, C. As técnicas Freinet da Escola Moderna. Lisboa: Estampa, 1973.

FREINET, C. Ensaios de Psicologia sensível. São Paulo: Martins Fontes, 1998

JULIÀ, D. A cultura escolar como objeto histórico. Revista Brasileira de História da Educação, Campinas, n. 1, p. 9-43, 2001.

LAMPERT-SHEPEL, E. The Definition of School Culture. S \& C III. Fall, 2008. From The Language of Learning: A Guide to Education Terms, by J. L. McBrien and R. S. Brandt. Alexandria, VA: Association for Supervision and Curriculum Development, 1997. p. 89.

LEITE, I. Emoções, sentimentos e afetos (Uma reflexão sócio-histórica). Araraquara: Junqueira \& Marin, 2005.

LEONTIEV, A. N.. O desenvolvimento do psiquismo. Lisboa: Horizontes, 1978a.

MARX, K; ENGELS, F. O Capital. Crítica da Economia Política. Livro 3, volume VII. 4. ed. Rio de Janeiro: Difel, 1984.

MARX, K; ENGELS, F. Actividad, Consciencia y Personalidad. Buenos Aires: Ciencias Del Hombre, 1978b.

MARX, K; ENGELS, F.Atividade, Consciência y Personalidad. Havana: Editorial Pueblo y Educación, 1980. 
MELLO, S. A. Infância e humanização: algumas considerações na perspectiva histórico-cultural. Perspectiva, Florianópolis, v. 25, n. 1, p. 83-104, jan./jun., 2007.

OLIVEIRA, Z. R de. Os primeiros passos na construção das idéias e práticas de educação infantil. In: OLIVEIRA, Z. R de. Educação Infantil: fundamentos e métodos. São Paulo: Cortez, 2002.

p. 57-70.

PLANO ESCOLAR. Escola de Educação Infantil e Ensino Fundamental Oca dos Curumins, São Carlos, 2011.

ROBBINS, P.; ALVY, H. The principal's companion. Thousand Oaks, CA: Corwin Press, 1995.

SAMPAIO, R. M. W. F. Freinet: evolução histórica e atualidades. 2. ed. São Paulo: Scipione, 1989.

VIÑAO FRAGO, A. Historia de la educación y historia cultural: posibilidades, problemas, cuestiones. Revista Brasileira de Educação, Rio de Janeiro, n. 0, p. 63-82, 1995.

VYGOTSKI, L. S. A brincadeira e o seu papel no desenvolvimento psíquico da criança. Tradução de Zoia Ribeiro Prestes. Revista Virtual de Gestão de Iniciativas Sociais, Rio de Janeiro, n. 8, p. 23-36, jun. 2008.

VYGOTSKI, L. S. A formação social da mente: o desenvolvimento dos processos psicológicos superiores. São Paulo: Martins Fontes, 2007.

VYGOTSKI, L. S. Pensamento e palavra. In: VYGOTSKI, L. S. Obras escogidas. Traducción de Lidia Kuper. Madrid: Visor, 2001b. v. II, p. 287-348.

\section{Como referenciar este artigo}

BARROS, Flávia Cristina Oliveira Murbach de. A teoria histórico-cultural e os pressupostos metodológicos de Celestin B. Freinet na educação infantil. Revista IberoAmericana de Estudos em Educação, Araraquara, v. 12, n. esp. 1, p.649-668, 2017. Disponível em: <http://dx.doi.org/10.21723/riaee.v12.n.esp.1.2017.9670>. E-ISSN: 1982-5587.

Submetido em: 07/03/2017

Aprovado em: 11/04/2017 